\title{
Powder Recycling Effects on the Tensile and Fatigue Behavior of Additively Manufactured Ti-6Al-4V Parts
}

\author{
PATRICIO E. CARRION, ${ }^{1,2}$ ARASH SOLTANI-TEHRANI, ${ }^{1,2}$ \\ NAM PHAN, ${ }^{3}$ and NIMA SHAMSAEI (i) ${ }^{1,2,4}$
}

1.-National Center for Additive Manufacturing Excellence (NCAME), Auburn University, Auburn, AL 36849, USA. 2.-Department of Mechanical Engineering, Auburn University, Auburn, AL 36849, USA. 3.-Structures Division, U.S. Naval Air Systems Command, Patuxent River, MD 20670, USA. 4.-e-mail: shamsaei@auburn.edu

\begin{abstract}
Additive manufacturing technology has enabled industries to generate functional parts with an increased level of complexity via layer-by-layer fabrication. In laser-powder bed fusion (L-PBF), powder is often recycled due to its high cost. However, there is no comprehensive study on how powder recycling affects its rheological properties, as well as the mechanical and fatigue behavior of the manufactured part. This study compares powder characteristics and mechanical performance of as-built and machined specimens fabricated from new and heavily used Ti-6Al-4V powder. Powder characteristics include particle size distribution and morphology, flowability, apparent density, compressibility, thermal conductivity, oxygen concentration, and more. Results indicate that particle size distribution becomes narrower and flowability increases with recycling. Not a significant effect of recycling was observed on the monotonic tensile and fatigue behavior of specimens in the asbuilt surface condition. However, machined specimens fabricated from used powder demonstrated longer fatigue lives in the high cycle regime.
\end{abstract}

\section{INTRODUCTION}

Additive manufacturing (AM) provides a unique opportunity to generate complex and/or customized parts. The two most common metal AM methods are directed energy deposition (DED) and powder bed fusion (PBF). In the PBF method, unlike subtractive conventional manufacturing, parts are fabricated in a layer-wise fashion using metallic powders. Laserpowder bed fusion (L-PBF), a type of PBF process, uses a laser as the energy source. In this process, the metal powder is spread over the substrate, and the laser fuses the new layer to the previously fabricated one in a selective manner. After the desired part is fabricated, the used powder can either be discarded or recycled. If recycled, the powder from the build envelope and collector bin is sieved to remove spatter or debris and then mixed with any remaining, unused powder in the feed bin. Due to the high cost of metallic powders, specifically Ti-6Al-4V, powder recycling can be a viable option for cost reduction. However, only few studies have been conducted on the powder recycling and its effects on the final mechanical and fatigue behavior of the fabricated part. ${ }^{1}$

Powder is defined as a finely divided solid that is smaller than $1 \mathrm{~mm}$ in its maximum dimension. ${ }^{2}$ Powder properties have been classified based on their morphology such as particle size, shape, and surface roughness; chemistry including the bulk and surface chemistry; and microstructure consisting of internal porosity and crystal structure. ${ }^{3-5}$ Properties such as particle size distribution (PSD), flowability, and oxygen content have been shown to affect the properties of the AM fabricated parts. ${ }^{1,6-14}$ For example, Nandwana et al. ${ }^{8}$ found that variations in PSD and apparent/bulk density affected the porosity of the parts fabricated from Ti$6 \mathrm{Al}-4 \mathrm{~V}$. Liu et al. ${ }^{10}$ concluded that a narrower PSD in 316L stainless steel increases flowability, leading to parts with higher ultimate tensile strength (UTS), and increased hardness. However, a wider PSD decreased flowability due to agglomerates formation as a result of higher friction between 
particles. It was also reported that wider PSD led to higher densities since finer particles can fill the vacancies between larger particles. ${ }^{10}$

Metal powder characteristics can also be affected by process conditions and environment. For instance, it has been observed that a humidity increase within the metallic powder may result in agglomeration and, consequently, an effect on flowability. ${ }^{2}$ In addition, it has been found that different mixtures of new and used powder (e.g., $25: 75,50: 50$, and 75:25) can affect the basic flowability energy (BFE), defined as the amount of energy required to move the blade within the powder, and that flowability does not change linearly with the amount of new powder in the mixture. ${ }^{15}$

Some recent studies have investigated the effects of recycling on the powder characteristics and, subsequently, the mechanical behavior of AM parts for different material systems such as stainless steels, ${ }^{16,17}$ Inconel $718^{18,19}$ and Ti-6Al-4V. ${ }^{7-9,19-23}$ Jacob et al. ${ }^{16}$ fabricated 11 similar L-PBF builds using new and used nitrogen atomized 17-4 $\mathrm{PH}$ stainless steel powder, and they evaluated hardness, tensile behavior, and surface roughness of the parts as the powder was reused. An increasing trend between flowability and apparent density with the number of recycling iterations was observed. No comparable change in powder PSD, particle shape, surface roughness, and mechanical behavior due to recycling was reported. Nezhadfar et al. ${ }^{17}$ compared the powder properties and mechanical behavior of parts fabricated from new, 5-, 10-, and 15-times recycled stainless steel 17-4. It was observed that the flowability of the powder recycled for five times was the highest amongst all batches. Additionally, an increase in reduction of area (RA) and elongation to failure was reported for the parts fabricated from 5-times recycled powder. Ardila et al. ${ }^{18}$ studied two L-PBF batches from new and 14-times used argon-atomized Inconel 718 powder. The recycling process involved sieving the powder to eliminate agglomerations and drying in the oven with air circulation to remove moisture. No comparable change was observed in the powder nor in the part properties including toughness, porosity, and microstructure. It was claimed that the recycling methodology was responsible for minimum differences between fabricated parts.

Similar studies conducted on Ti-6Al-4V powder recycling have reported changes in powder PSD, flowability, oxygen content, and particle shape. Seyda et al. ${ }^{9}$ found a narrower PSD, increased flowability, and apparent density, after 12 recycling iterations. An increase in surface roughness, overall size of the pores, and a reduction in total number of pores in the L-PBF Ti-6Al-4V fabricated samples were also reported. In addition, a small increase in the hardness of parts fabricated from used powder was observed, which was attributed to the powder oxidization, and trapped oxygen atoms in the melt pool during fabrication. This oxygen pick-up was credited to the exposure of the powder to the atmosphere during sieving and parts removal from the chamber. O'Leary et al. ${ }^{20}$ found that the number of particles less than $15 \mu \mathrm{m}$ decreased, while particles larger than $45 \mu \mathrm{m}$ increased after five recycling cycles. No changes in the interstitial oxygen and nitrogen contents within the powder composition were reported. However, a noticeable amount of absorbed oxygen was found in the L-PBF manufactured parts, which was the highest for build one, and it exceeded the allowable oxygen content (i.e., 0.2 wt.\%) for Ti-6Al-4V grade 5 and 23 specified by the ASTM F2924-14 Standard. $^{24}$ The amount of oxygen content within the parts was shown to decrease with recycling.

Nandwana et al. ${ }^{19}$ fabricated Ti-6Al-4V parts via electron beam melting (EBM) and reported no substantial change in PSD and flowability of the powder after five recycling iterations. Although an increase in oxygen content of the powder and part was noticed as the powder was recycled, the overall oxygen content was still below the acceptable value according to the ASTM F2924-14 Standard. ${ }^{24}$ In another study of Ti-6Al-4V parts fabricated via $\mathrm{EBM},{ }^{7}$ powder was recycled 21 times. Results showed a slight increase in the oxygen content of the powder due to recycling. It was also seen that the powder particles became less spherical, while tensile properties of the produced specimens were not affected.

The aforementioned studies have demonstrated changes in powder characteristics due to recycling and the subsequent effects on the porosity and in some cases static mechanical properties. However, depending on the application, AM parts may be under cyclic loading. Therefore, there is a need to evaluate the fatigue performance of parts fabricated using recycled (i.e., used) powder to help with qualification and certification of AM products. ${ }^{25-28}$ In this study, the rheological properties of new and heavily recycled Ti-6Al-4V powder are characterized. The L-PBF specimens are then subjected to quasi-static tensile and fatigue loading. Finally, an attempt is made to correlate the mechanical testing results with the changes in the powder characteristics.

\section{EXPERIMENTAL PROGRAM}

\section{Material and Powder Characterization}

Gas-atomized Ti-6Al-4V Grade 23 powder manufactured by LPW Technology with a particle size distribution of 15-45 $\mu \mathrm{m}$ (as reported by the manufacturer) was used for this study. The powder was used in two conditions; new (i.e., virgin) and used (recycled for 15 times). It is also important to mention that the recycling procedure involved filtering the used powder with an $80-\mu \mathrm{m}$ mesh size sieve after each print. Particle size distribution analysis was conducted via a Malvern Mastersizer 3000 Hydro EV laser diffraction, as suggested by the 
ASTM E2651-13 Standard. ${ }^{29}$ The powder used for characterization was sampled according to the ASTM B215-15 Standard ${ }^{30}$ by taking equal increments from different depths of the container. The thermal conductivity of both powder samples was analyzed using a C-Therm TCi thermal analyzer. A Freeman Technology FT4 powder rheometer was used to analyze powder characteristics including permeability, compressibility, density, and aeration. In addition, the interstitial gas content of the material including oxygen and nitrogen was further analyzed by an inert gas fusion method via LECO ONH-836 following the ASTM E1409-13 Standard. ${ }^{31}$

\section{Specimen Fabrication}

Laser-powder bed fusion Ti-6Al-4V specimens were fabricated using an EOS M290 system in two separate batches, one from new (i.e., never used powder) and one from heavily used powder (i.e., recycled for 15 times). The number of prints may not have much meaning here because different parts were printed with the used powder batch. EOS default process parameters were used, including $280 \mathrm{~W}$ laser power, $1,200 \mathrm{~mm} / \mathrm{s}$ travel speed, $100 \mathrm{~mm}$ stripe width, $140 \mu \mathrm{m}$ hatch spacing, $67^{\circ}$ hatch rotation, and a $30-\mu \mathrm{m}$ layer thickness. Netshape round specimens with a uniform gage section having a $3.75-\mathrm{mm}$ gage diameter and a $15-\mathrm{mm}$ gage length were fabricated vertically (i.e., $90^{\circ}$ from the build plate) with argon as the shielding gas. In addition, 11-mm square rods were fabricated vertically on the same build plate. After fabrication, all parts were stress relieved at $704^{\circ} \mathrm{C}$ in an argon atmosphere for $1 \mathrm{~h}$ and then air cooled to room temperature. Post stress relief, the 11-mm-squared rods were machined to the same geometry as the net-shape specimens; then the gage section was polished to a $0.45-\mu \mathrm{m}$ surface finish, hereon referred to as a "machined" (M) condition. No further polishing was done to the net-shape specimens after heat treatment; therefore, it was considered to be in the "as-built" $(\mathrm{AB})$ condition. It is important to emphasize that the only two variables were the Ti$6 \mathrm{Al}-4 \mathrm{~V}$ powder (i.e., new and used) and the surface condition (i.e., as-built and machined); a great effort was put into keeping all other variables, such as specimen layout on the build plate, shielding gas, etc., consistent.

\section{Mechanical Testing and Fractography}

Quasi-static tensile and strain-controlled fatigue tests were conducted using an MTS 810 servohydraulic system. An MTS extensometer with a 10$\mathrm{mm}$ gage length was used to record strain and run strain-controlled fatigue tests. Tensile tests, based on the ASTM E8 Standard, ${ }^{32}$ were performed at the strain rate of $0.001 \mathrm{~s}^{-1}$ on four as-built specimens, two of which were fabricated from new powder and two from used powder. It is important to mention that specimens with the same geometry designed for fatigue testing were used for tensile testing.

Fully reversed $\left(R_{\varepsilon}=-1\right)$ strain-controlled fatigue tests were conducted according to the ASTM E606 Standard. ${ }^{33}$ The strain amplitude values, $\varepsilon_{a}$, selected for this study were $0.001 \mathrm{~mm} / \mathrm{mm}, 0.003$ $\mathrm{mm} / \mathrm{mm}$, and $0.005 \mathrm{~mm} / \mathrm{mm}$ for as-built specimens and $0.004 \mathrm{~mm} / \mathrm{mm}, 0.005 \mathrm{~mm} / \mathrm{mm}$, and $0.007 \mathrm{~mm} /$ $\mathrm{mm}$ for machined specimens. These strain amplitudes were selected as they cover low, mid, and high cycle fatigue (HCF) regimes. The test frequency was adjusted for each $\varepsilon_{\alpha}$ to eliminate strain rate effects on the fatigue behavior. Fatigue experiments that reached over $2 \times 10^{7}$ reversals were stopped. At least three fatigue tests for each strain amplitude were conducted for verification of results. Specimens from the same location on the build plate, but from different builds (i.e., with new and used powder), were tested under the same parameters and conditions. Fractography analysis was performed on failed specimens using a Keyence VHX6000 digital microscope. Each fracture surface was examined to find defects such as gas pores or other phenomena responsible for crack initiation and subsequent propagation prior to final fracture.

\section{EXPERIMENTAL RESULTS AND OBSERVA- TIONS}

\section{Powder Characteristics}

The particle size distributions of new and used powder samples are presented in Fig. 1a. As seen in the figure, the distribution becomes narrower for the used powder. This can be explained by the gap between the wiper/recoater and the substrate not being larger than $50 \mu \mathrm{m}$; hence, finer particles (smaller than $50 \mu \mathrm{m}$ ) are spread on the build plate and participate in the melting and solidification processes during manufacturing. However, particles greater than $50 \mu \mathrm{m}$ may be transferred to the collector bin. After completion of each print, the powder is sieved and mixed with the remainder of the powder in the feed bin. Repeating this procedure will lead to narrower PSDs as particles that are smaller than $50 \mu \mathrm{m}$ are melted and solidified, while larger particles get filtered when going through the $80-\mu \mathrm{m}$ mesh size screen. This may also be explained from Fig. 1b, where the particle diameters within a sample of the new or used powder are measured five times and classified according to D90, D50, and D10 values. For example, in the figure, D90 indicates that $90 \%$ of the particles within the powder sample are less than $64 \mu \mathrm{m}$ for the new powder and $52 \mu \mathrm{m}$ for the used powder. Results show that the D90 and D50 of the new powder are larger than the ones of the used powder, indicating the filtration of larger particles while going through the sieve screen. However, the D10 values are approximately the same for both powder samples. Similar trends on the narrower PSD after recycling were also reported in Ref. 7. 


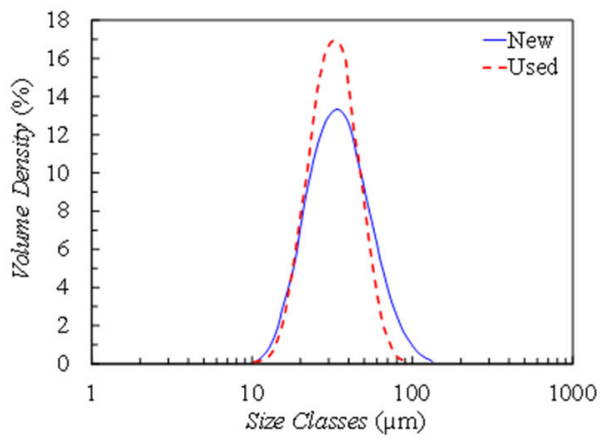

(a)

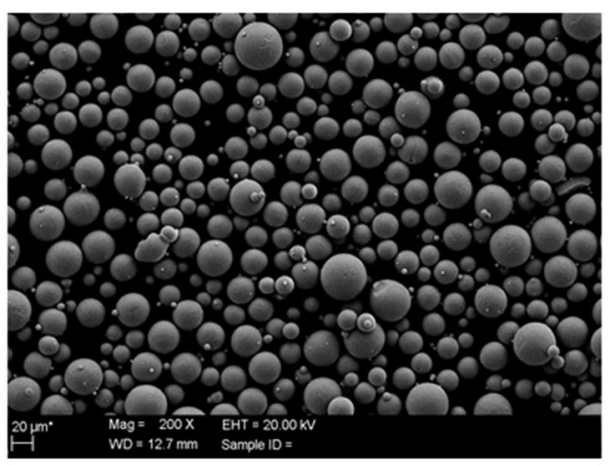

(c)

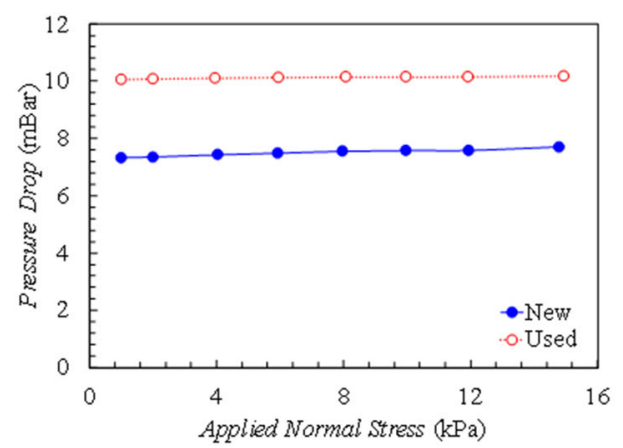

(e)

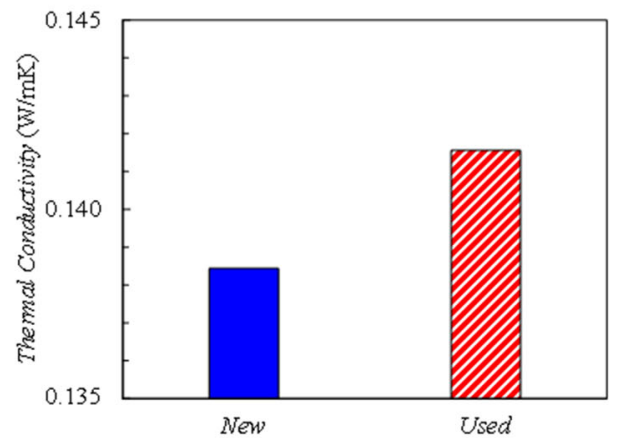

(g)

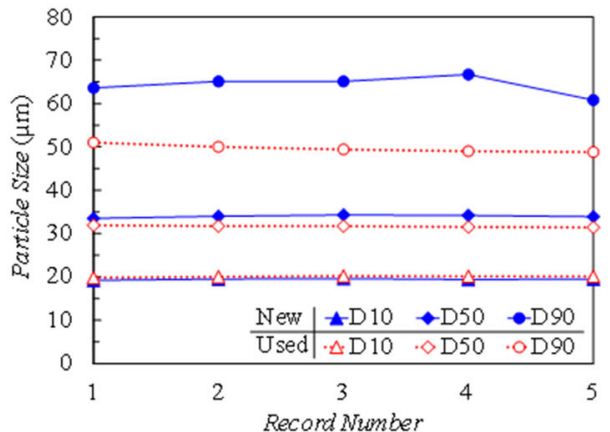

(b)

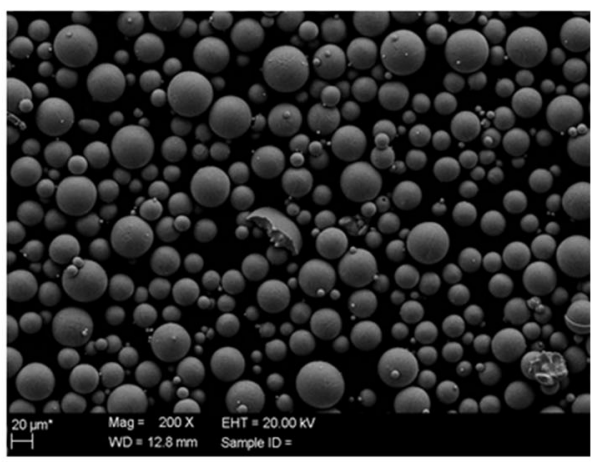

(d)

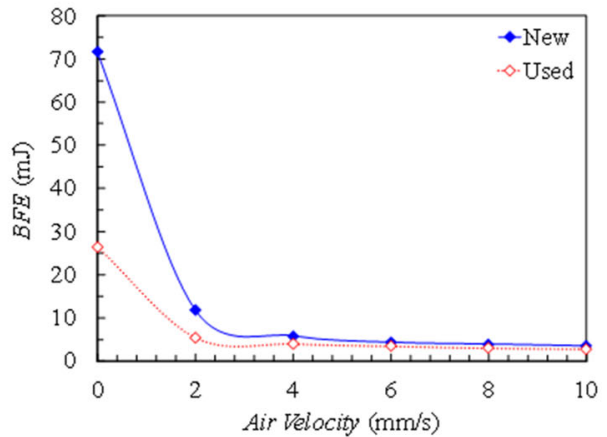

(f)

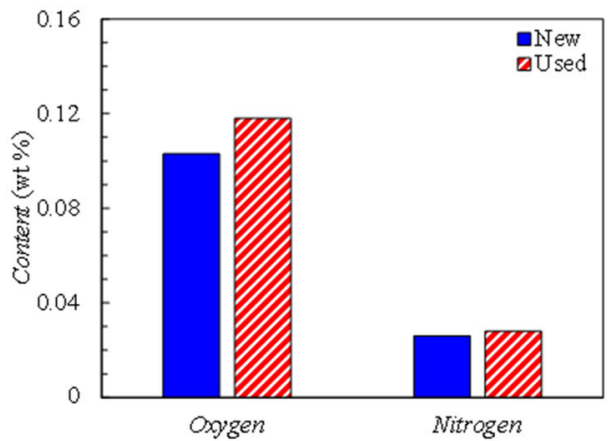

(h)

Fig. 1. Comparison of new and used Ti-6Al-4V powder properties: (a) particle size distribution (PSD), adapted from Ref. 22; (b) D values of particles (D10, D50, D90); (c) new; and (d) used particle morphologies obtained via SEM, (e) pressure drop versus applied normal stress within the powder bulk, (f) basic flowability energy (BFE), (g) thermal conductivity, and (h) interstitial gas contents. 
Representative powder morphology, obtained via scanning electron microscopy (SEM), is shown in Fig. 1c and d, respectively, for new and used powder. Results indicate that fewer "satellites," i.e., smaller particles attached to the larger particles, ${ }^{1}$ were observed in the used powder when compared to the new one. It was also observed that most particles remain spherical after being recycled. Permeability has an inverse correlation with pressure drop versus applied normal stress, which is shown in Fig. 1e. The permeability of the powder bulk is a measure of how easily a fluid (i.e., argon gas) can flow between the powder particles, which can correlate to the powder flowability. ${ }^{34}$ The permeability of the used powder is lower than the new powder as the pressure drop of the used powder is higher than new powder, as seen in Fig. 1e. In addition, the BFE of both powder samples, which can help to quantitatively characterize the flow resistance during constrained circumstances, is shown in Fig. 1f. The BFE of the used powder is lower than new powder, indicating the better flowability of the used powder.

Metal powder thermal conductivity, $k$, plays a significant role in the AM process. Different $k$ values may lead to different cooling rates and thermal histories. The thermal conductivity of both powder samples is shown in Fig. 1g, where a slight increase in thermal conductivity of used powder is observed. The measured thermal conductivities in this study are close to the value reported in Ref. 35 for Ti-6Al-4V powder at 1 bar. The interstitial gas content of the powder is shown in Fig. 1h. As it can be observed, the oxygen content has slightly increased due to recycling. This can be elucidated by the intrinsic essence of $\mathrm{Ti}-6 \mathrm{Al}-4 \mathrm{~V}$ to react with oxygen. ${ }^{19,36}$ However, the nitrogen content remained almost constant.

\section{Microstructure and Tensile Behavior}

The microstructure of L-PBF Ti-6Al-4V specimens fabricated from new and used powder is shown in Fig. 2a and b, respectively. As can be seen in these figures, there are no significant differences between grain morphologies. Both microstructures are composed of a fine acicular $\alpha^{\prime}$ microstructure within the columnar prior- $\beta$ grains oriented parallel to the build direction. Since negligible differences in grain size, shape, and distribution were observed, powder recycling is not considered to have much effect on grain morphological features.

Quasi-static tensile stress-strain curves of L-PBF Ti-6Al-4V specimens fabricated from new and used powder batches are presented and compared to the one of wrought Ti-6Al- $4 \mathrm{~V}^{37}$ in Fig. 3. It may be seen that the yield and ultimate tensile strengths of LPBF Ti-6Al-4V are higher $(10 \%$, and $5 \%$, respectively) than the ones of the wrought counterpart, while their elongation to failures are similar. Tensile stress-strain results show no significant

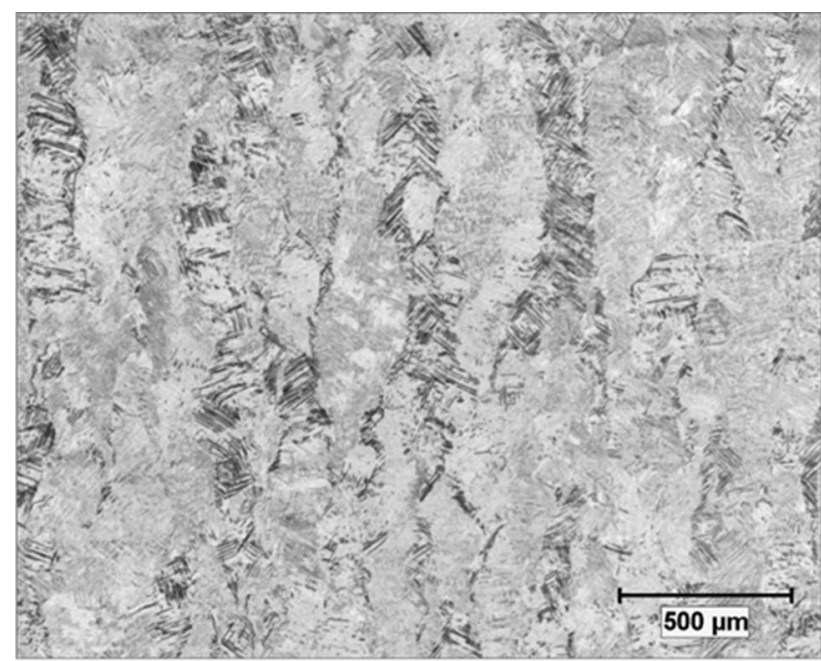

(a)

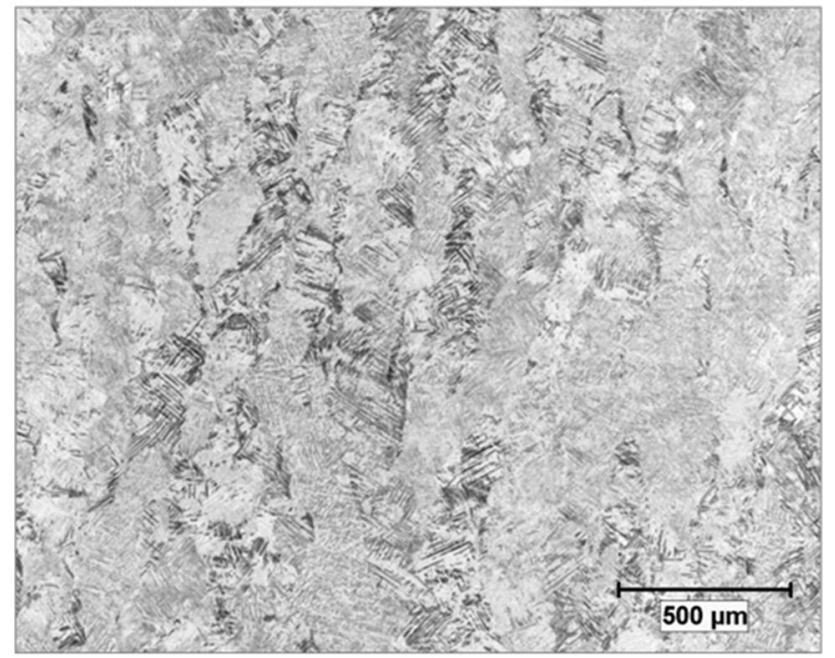

(b)

Fig. 2. Microstructure images of L-PBF Ti-6Al-4V specimens fabricated with (a) new and (b) used powder.

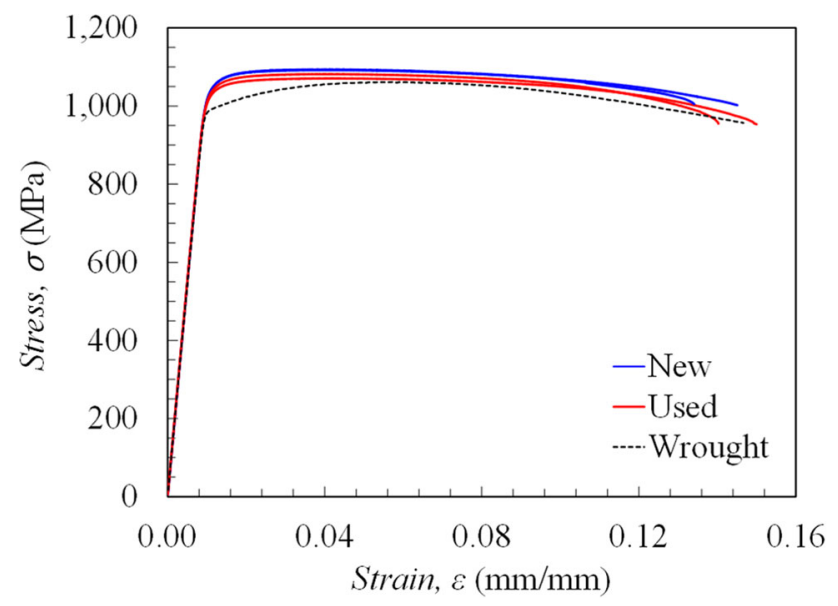

Fig. 3. Tensile deformation comparison of L-PBF Ti-6Al-4V specimens fabricated with new and used powder, adapted from Ref. 22 as well as with wrought Ti-6Al-4V, adapted from Ref. ${ }^{37}$. 
changes in yield and ultimate tensile strength, neither in elongation to failure for specimens fabricated from new and used powder.

\section{Fatigue Behavior}

Strain-controlled fatigue test results of L-PBF Ti$6 \mathrm{Al}-4 \mathrm{~V}$ specimens fabricated from new and used powder are presented in Table I. Included in the table are the surface conditions (i.e., as-built $(\mathrm{AB})$ or machined (M)), first cycle modulus of elasticity, $E$, strain amplitude, $\varepsilon_{\alpha}$, mid-life stress amplitude, $\sigma_{a}$, and mean stress, $\sigma_{m}$, as well as the number of reversals to failure, $2 N_{f}$.

Semi-log plots of $\varepsilon_{a}$ versus $2 N_{f}$ for the as-built and machined specimens are presented in Fig. $4 \mathrm{a}$ and b, respectively. In addition, $\sigma_{a}$ versus $2 N_{f}$ semi-log plots for the as-built and machined specimens can be seen in Fig. 4c and d. Horizontal arrows indicate experiments for which the fatigue life reached over $2 \times 10^{7}$ reversals with "no failure." As seen in Fig. 4a, fatigue lives of new and used powder specimens in the as-built condition are similar at $\varepsilon_{a}=0.005 \mathrm{~mm} / \mathrm{mm}$ and $0.003 \mathrm{~mm} / \mathrm{mm}$ without much scatter. However, at $\varepsilon_{a}=0.001 \mathrm{~mm} / \mathrm{mm}$, i.e., high cycle regime, a wide scatter is seen for both specimen sets, although again no effect of powder recycling can be noticed. As seen in Fig. 4c, the stress amplitude values of new and used powder specimens in the as-built condition showed no differences. Neither beneficial nor detrimental effects of powder recycling on the fatigue behavior

Table I. Summary of fully-reversed strain-controlled fatigue tests for L-PBF Ti-6Al-4V specimens fabricated with new and used powder. Specimens were tested in the as-built $(A B)$ and machined (M) surface conditions

\begin{tabular}{|c|c|c|c|c|c|}
\hline Surface condition $\mathbf{A B} / \mathbf{M}$ & $E \mathbf{G P a}$ & $\varepsilon_{\mathbf{a}} \mathbf{m m} / \mathbf{m m}$ & $\sigma_{\mathbf{a}} \mathbf{M P a}$ & $\sigma_{\mathbf{m}}$ MPa & $2 N_{f}$ reversals \\
\hline \multicolumn{6}{|l|}{ New powder } \\
\hline $\mathrm{AB}$ & 111 & 0.005 & 622 & -6 & 6,316 \\
\hline $\mathrm{AB}$ & 111 & 0.005 & 626 & 5 & 7,964 \\
\hline $\mathrm{AB}$ & 109 & 0.005 & 609 & 23 & 8,040 \\
\hline $\mathrm{AB}$ & 110 & 0.003 & 374 & -3 & 37,404 \\
\hline $\mathrm{AB}$ & 108 & 0.003 & 368 & -6 & 37,782 \\
\hline $\mathrm{AB}$ & 110 & 0.003 & 374 & -12 & 38,360 \\
\hline $\mathrm{AB}$ & 111 & 0.001 & 121 & 5 & $1,057,596$ \\
\hline $\mathrm{AB}$ & 109 & 0.001 & 116 & -2 & $1,128,944$ \\
\hline $\mathrm{AB}$ & 109 & 0.001 & 123 & 1 & $>20,013,686$ \\
\hline $\mathrm{M}$ & 119 & 0.007 & 824 & 3 & 17,384 \\
\hline M & 119 & 0.007 & 844 & -13 & 27,192 \\
\hline M & 119 & 0.007 & 831 & -7 & 30,288 \\
\hline M & 120 & 0.005 & 601 & -5 & 173,508 \\
\hline $\mathrm{M}$ & 119 & 0.005 & 597 & -1 & 449,698 \\
\hline M & 120 & 0.005 & 599 & -6 & 949,348 \\
\hline M & 119 & 0.004 & 479 & 3 & 250,248 \\
\hline $\mathrm{M}$ & 120 & 0.004 & 484 & -2 & $1,264,620$ \\
\hline $\mathrm{M}$ & 118 & 0.004 & 468 & 4 & $1,547,480$ \\
\hline $\mathrm{M}$ & 119 & 0.004 & 478 & 4 & $1,670,566$ \\
\hline \multicolumn{6}{|l|}{ Used powder } \\
\hline $\mathrm{AB}$ & 108 & 0.005 & 615 & -11 & 7,528 \\
\hline $\mathrm{AB}$ & 109 & 0.005 & 606 & -4 & 7,822 \\
\hline $\mathrm{AB}$ & 110 & 0.005 & 624 & -7 & 8,924 \\
\hline $\mathrm{AB}$ & 110 & 0.003 & 369 & 1 & 27,848 \\
\hline $\mathrm{AB}$ & 109 & 0.003 & 354 & -4 & 37,920 \\
\hline $\mathrm{AB}$ & 110 & 0.003 & 365 & -4 & 44,080 \\
\hline $\mathrm{AB}$ & 110 & 0.001 & 120 & 1 & 722,494 \\
\hline $\mathrm{AB}$ & 110 & 0.001 & 122 & -4 & $>20,065,918$ \\
\hline $\mathrm{AB}$ & 109 & 0.001 & 122 & 0 & $>20,742,612$ \\
\hline $\mathrm{M}$ & 121 & 0.007 & 845 & -11 & 14,978 \\
\hline $\mathrm{M}$ & 118 & 0.007 & 827 & -1 & 15,192 \\
\hline M & 119 & 0.007 & 831 & -1 & 25,356 \\
\hline M & 120 & 0.005 & 600 & 1 & 69,198 \\
\hline M & 119 & 0.005 & 597 & -7 & 75,938 \\
\hline $\mathrm{M}$ & 120 & 0.005 & 602 & 12 & $1,230,696$ \\
\hline M & 120 & 0.004 & 479 & -3 & $8,657,266$ \\
\hline M & 120 & 0.004 & 480 & -3 & $9,448,566$ \\
\hline M & 120 & 0.004 & 481 & 1 & $9,833,200$ \\
\hline $\mathrm{M}$ & 119 & 0.004 & 480 & 2 & $>20,034,406$ \\
\hline
\end{tabular}




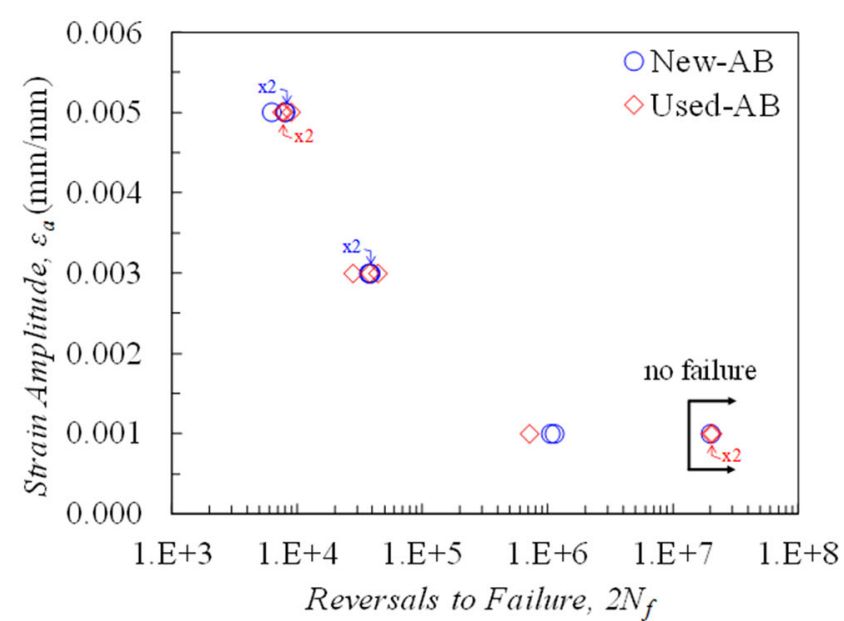

(a)

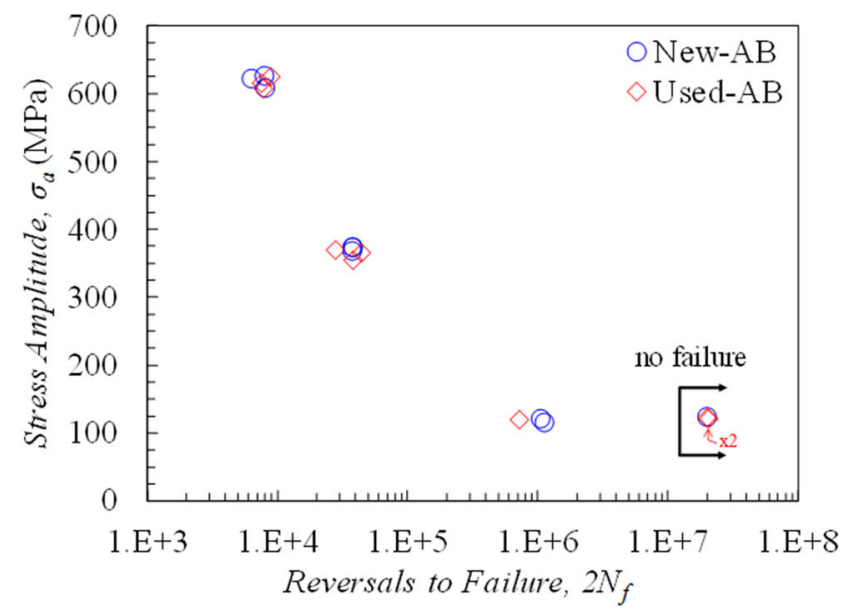

(c)

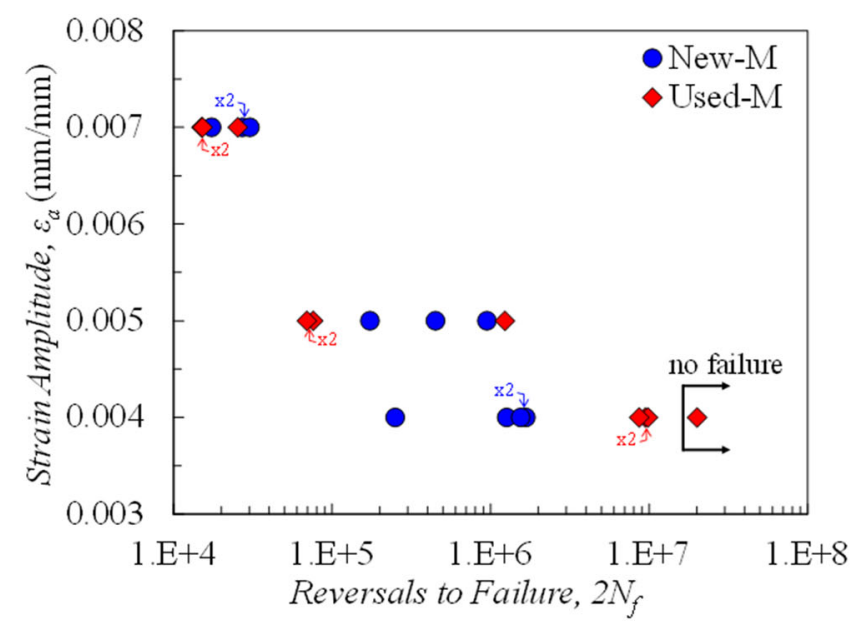

(b)

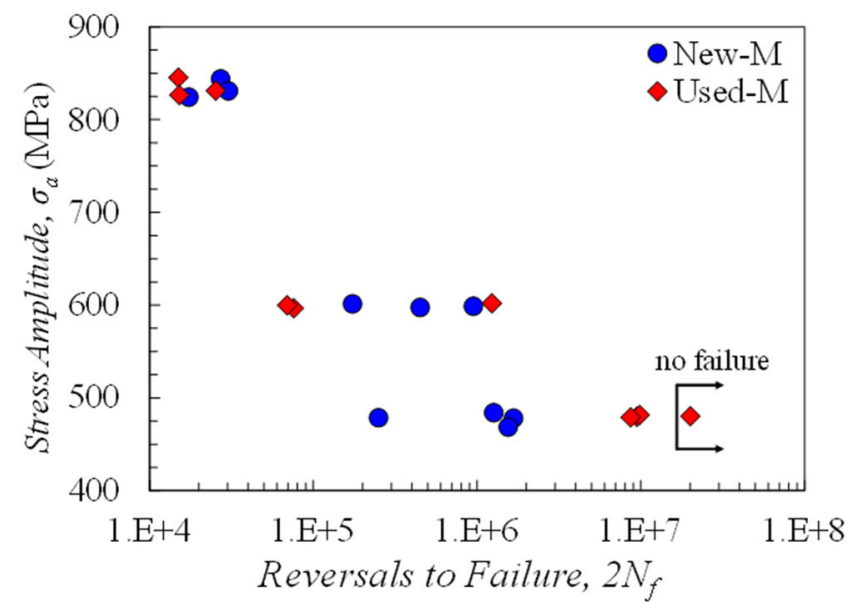

(d)

Fig. 4. Strain-life comparison of L-PBF Ti-6Al-4V specimens fabricated with new and used powder in (a) as-built (AB), adapted from Ref. 22 and (b) machined (M) surface conditions. Stress-life comparison in (c) $A B$ and (d) M surface conditions.

can be concluded for specimens with the as-built surface condition.

As seen in Fig. $4 \mathrm{~b}$, machined specimens fabricated from new and used powder batches exhibit similar strain-life fatigue behaviors at $\varepsilon_{a}=0.007$ $\mathrm{mm} / \mathrm{mm}$. At $\varepsilon_{a}=0.005 \mathrm{~mm} / \mathrm{mm}$, however, a wide scatter in both datasets can be noticed, and the results indicate neither beneficial nor detrimental effects of powder recycling. Remarkable differences can be observed at $\varepsilon_{a}=0.004 \mathrm{~mm} / \mathrm{mm}$ as the fatigue lives of machined specimens fabricated from used powder are significantly longer than the ones of specimens fabricated from new powder. Finally, negligible differences in the stress amplitude values of machined specimens fabricated from new and used powder were observed, as shown in Fig. 4d. In conclusion, it appears that recycling the powder may improve the fatigue resistance of machined L$\mathrm{PBF}$ Ti-6Al-4V specimens in the high cycle regime.

\section{Fractography Analysis}

Digital microscopy was used on the fracture surfaces to identify crack initiations from any internal pores or surface defects for as-built and machined specimens fabricated from new and used powder batches. For as-built specimens, it was found that all failures originated from micronotches on the rough surface of specimens regardless of being fabricated from new or used powder. An example is shown in Fig. 5 for a specimen fabricated from used powder and tested under $0.001-\mathrm{mm} / \mathrm{mm}$ strain amplitude. As can be seen, there are at least five crack initiation sites (indicated by the red arrows) in proximity of each other on the fracture surface. The crack propagation region is outlined by the dashed line.

For machined specimens, cracks initiated from internal, often close-to-surface pores. In some cases, cracks were observed to initiate from pores brought 


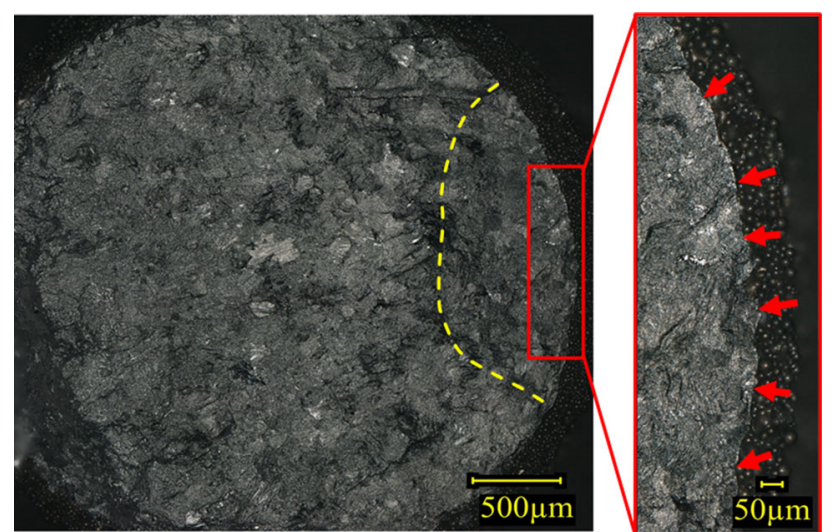

Fig. 5. Fracture surface of a L-PBF Ti-6AI-4V specimen fabricated with used powder in the as-built condition tested under straincontrolled fully reversed $0.001-\mathrm{mm} / \mathrm{mm}$ strain amplitude with a fatigue life of 722,494 reversals. Crack initiation locations are shown with arrows.

to the surface by the machining process. Examples for machined specimens tested at $\varepsilon_{a}=0.005 \mathrm{~mm} /$ $\mathrm{mm}$ are shown in Fig. 6a, b, and c. An enhanced view of the crack initiation site for each fracture surface is also included. The dashed lines in these figures mark the transition from the crack propagation stage to the final fracture stage of fatigue. Figure 6 a shows crack initiation from a defect with the size of $3730 \mu \mathrm{m}^{2}$ on the fracture surface of a specimen fabricated from used powder and a fatigue life of 69,198 reversals. Figure $6 \mathrm{~b}$ shows crack initiation from a surface defect with the size of $774 \mu \mathrm{m}^{2}$ (a pore that was brought to the surface by machining) for a specimen fabricated from used powder with a fatigue life of 75,938 reversals. Finally, Fig. 6c shows crack initiation from an internal pore with the size of $1603 \mu \mathrm{m}^{2}$ on the facture surface of a specimen fabricated from used powder with a fatigue life of 1,230,696 reversals. Although no trend between powder batches and the type of defects was found, one could conclude that the combination of defect size and location was the major factor affecting the fatigue life of specimens regardless of being fabricated from new or used powder.

\section{DISCUSSION ON EXPERIMENTAL OBSER- VATIONS}

The existence of finer particles in the powder batch may contribute to defect formation as they spatter easier from the deposited layer when the laser scans the selected area. ${ }^{7}$ On the other hand, the existence of the same finer particles in the powder batch can fill the void spaces between larger particles, which may lead to less porosity in the fabricated part. $1,4,10,38,39$ Therefore, other powder characteristics such as flowability need to be taken into consideration when reporting powder specifications. ${ }^{1,7,9-11,16,19}$ In addition to PSD, powder flowability can play a big role in the quality of fabricated parts. It has been reported that a wider PSD may impede the powder flow by forming agglomerates because of higher interparticle frictions of the finer particles. ${ }^{1,2,10}$ It may be assumed that the new powder with higher permeability, shown in Fig. 1e, can flow better. However, due to the wider PSD and existence of finer particles, the new powder tends to move with more agglomerates.

The new powder tendency to move in agglomerates may also be explained by the BFE level, as shown in Fig. 1f. Accordingly, more energy is required to flow the new powder as compared to the used one, indicating less flowability of the new powder. In addition, apparent density was found to be lower for the new powder compared to the used powder (2\% difference), which can be attributed to the relatively higher interparticle frictions and cohesion in the new powder, as also reported by Seyda et al. ${ }^{9}$ As a result of wider PSD, larger BFE and smaller apparent density of the new powder, there might be a more uneven layer distribution of the powder on the build plate that can potentially cause more defects in the final part. $1,2,11,15,40$

As shown earlier, changes in mechanical properties (e.g., yield strength) of specimens fabricated from new and used powder were negligible. These results differ from other studies such as Tang et al., ${ }^{7}$ where the yield and ultimate tensile strength increased with powder recycling iterations due to higher oxygen content in Ti-6Al-4V parts produced by EBM. Seyda et al. ${ }^{9}$ observed a decrease in ultimate tensile strength with recycling iterations due to the formation of larger pores near the surface of the L-PBF Ti-6Al-4V specimens. However, based on the results presented by Quintana et al. ${ }^{36}$ for LPBF Ti-6Al-4V on the effects of oxygen content, and Jacob et al. ${ }^{16}$ for L-PBF 17-4 PH stainless steel on the effects of powder recycling, the changes in yield and ultimate tensile strength were negligible. Therefore, from the quasi-static tensile test results, it may be concluded that a slight change in oxygen content may not have a significant effect on the tensile properties of L-PBF Ti-6Al-4V. The variation in the powder PSD, flowability, and compressibility may change the porosity level of fabricated parts. However, the change was not significant enough to affect their tensile behavior. This is due to the severe plastic deformation occurring under monotonic loading, which may diminish the material sensitivity to defects.

The fatigue results for specimens fabricated from new and used powder in the as-built surface condition, presented earlier, may be explained by the fact that fatigue failure is often dominated by surface roughness, which provides the opportunity for cracks to initiate from the micro-notches on the surface rather than from internal defects. ${ }^{41}$ Surface roughness measurements revealed that specimens fabricated from new and used powders had slight 
Powder Recycling Effects on the Tensile and Fatigue Behavior of Additively Manufactured Ti6Al-4V Parts

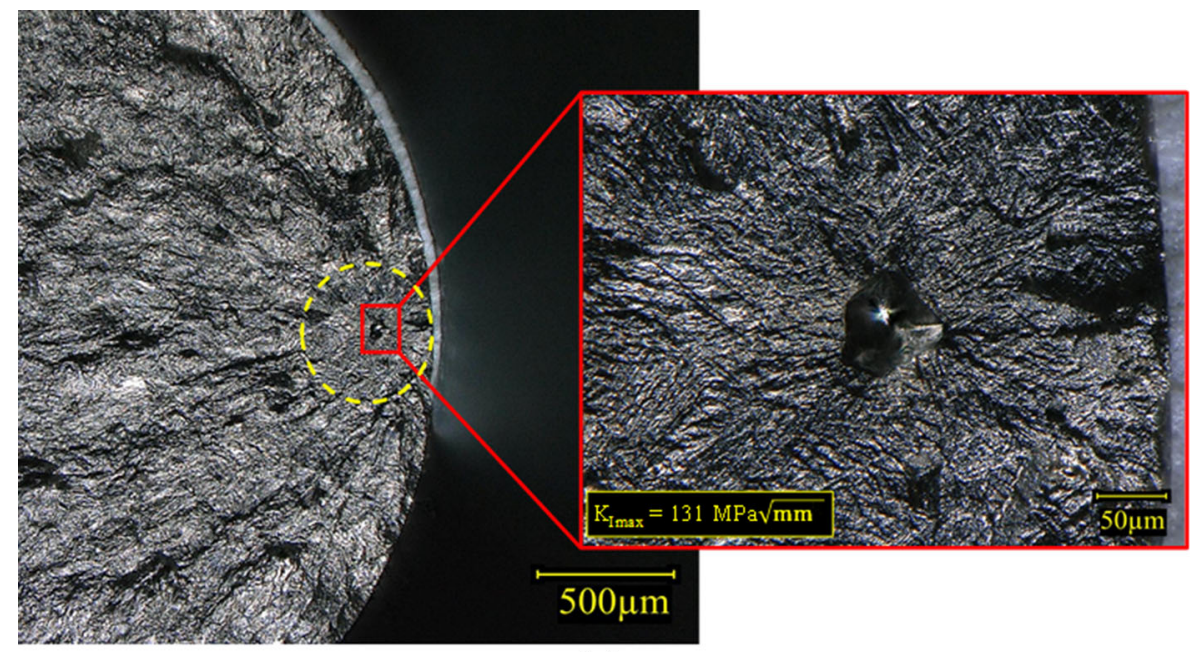

(a)

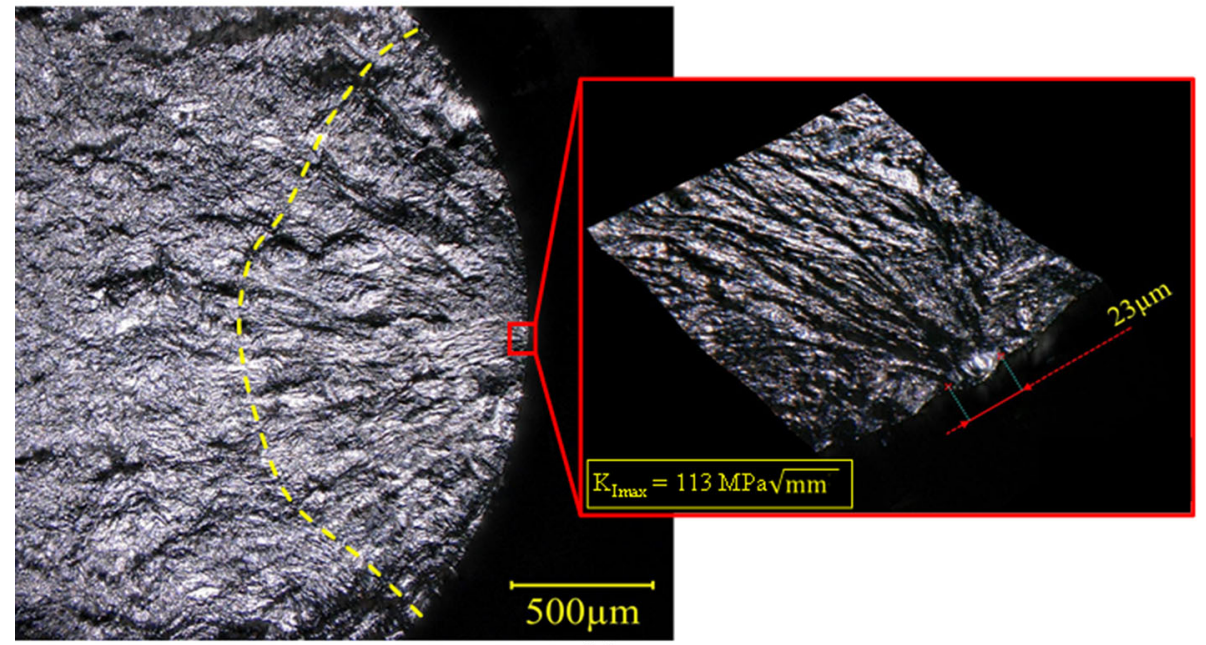

(b)

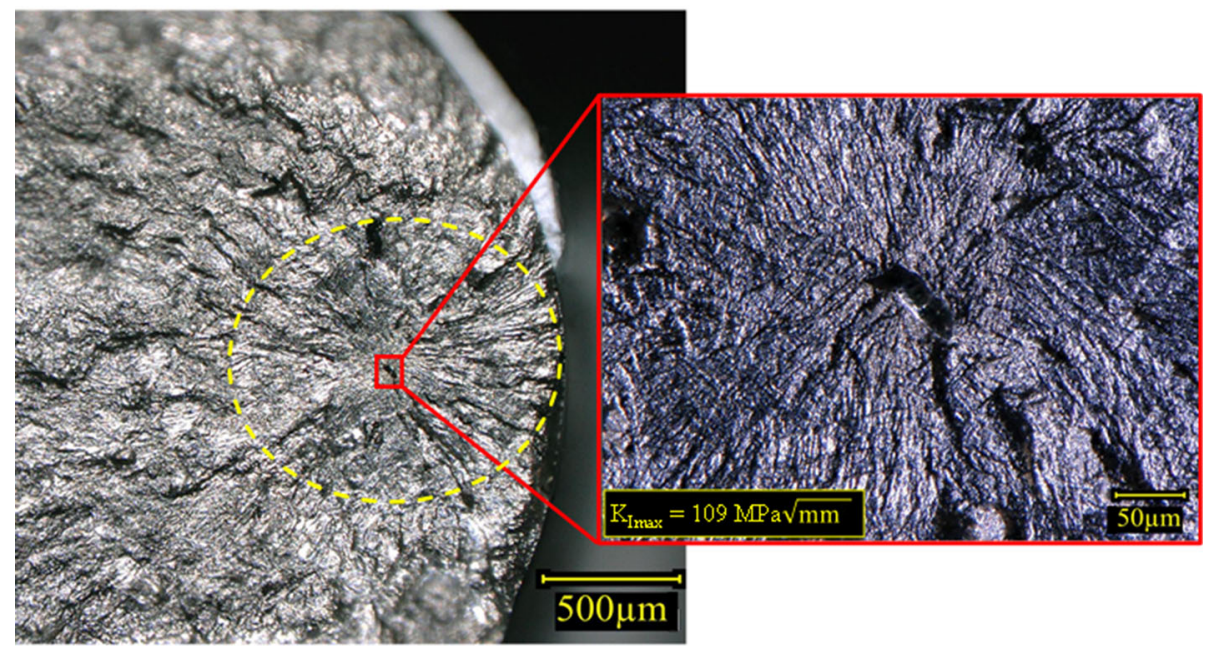

(c)

Fig. 6. Fracture surfaces showing crack initiation sites for L-PBF Ti-6Al-4V specimens fabricated with used powder in the machined surface condition tested under fully-reversed $0.005 \mathrm{~mm} / \mathrm{mm}$ strain amplitude, achieving a fatigue life of (a) 69,198 reversals, (b) 75,938 reversals, and (c) $1,230,696$ reversals. 
differences in average surface roughness values: an $R_{a}$ of $19 \mu \mathrm{m}$ and $16 \mu \mathrm{m}$, respectively. However, after gently polishing the gage surface to remove any adhered powder or partially melted particles, the surface roughness values appeared to be similar with an $R_{a}=15 \mu \mathrm{m}$. The initial differences in surface roughness values may be explained by the variation of thermal effusivity, $e$, and thermal conductivity, $k$ between new and used powder. Because of the lower thermal conductivity (see Fig. 1g) and apparent density, thermal effusivity of the new powder was lower than the used powder, indicating less heat transfer with the surrounding environment and, therefore, a higher heat accumulation in the new powder particles. Although more investigations are needed, one may conclude that the higher heat accumulation in the powder particles in proximity to the fabricated part causes them to partially melt, fuse together, and attach to the surface of the part, which increases the surface roughness. ${ }^{41,42}$ However, after gently polishing the specimens fabricated from new and used powder, the surface roughness values were measured to be the same, justifying similar fatigue behaviors observed for as-built specimens fabricated.

As presented earlier, significantly longer fatigue lives at $\varepsilon_{a}=0.004 \mathrm{~mm} / \mathrm{mm}$ were observed for machined specimens fabricated from used powder as compared to the specimens fabricated from new powder. Since the specimens were machined and polished, internal defects play a major role in crack initiation, specifically in the high cycle fatigue regime (i.e., $\varepsilon_{a}=0.004 \mathrm{~mm} / \mathrm{mm}$ ). The longer fatigue lives of specimens fabricated from used powder may be explained by the combination of increased flowability (i.e., lower cohesion between particles) and lower compressibility (i.e., less/smaller empty spaces within the powder) leading to a more uniform layer distribution on the powder bed and possibly smaller pores within the fabricated part.

For the fractography analysis results presented earlier, the Murakami approach ${ }^{43}$ was used to characterize the main defect that caused fatigue failure. This approach allows for correlation of fatigue life to the maximum stress intensity factor, $K_{I, \max }$, with a higher stress intensity factor implying a shorter fatigue life. The Murakami approach takes into account the defect size by using the effective area of the defect and the relative location of the defect by introducing a shape factor, Y, of 0.65 for surface defects and of 0.5 for internal defects. For example, the specimen shown in Fig. 6a with a fatigue life of 69,198 reversals had a $K_{\text {I,max }}=131 \mathrm{MPa} \sqrt{\mathrm{mm}}$; the one in Fig. $6 \mathrm{~b}$ with a fatigue life of 75,938 reversals had a $K_{\text {I,max }}=113 \mathrm{MPa} \sqrt{\mathrm{mm}}$; and the one in Fig. 6c with a fatigue life of 1,230,696 reversals had a $K_{\text {I,max }}=109 \mathrm{MPa} \sqrt{\mathrm{mm}}$, which explains the differences observed in fatigue lives. Other studies such as Refs. ${ }^{44-48}$ have also shown good correlation between stress intensity factor and resultant fatigue life using the Murakami approach.

Since no correlation between the main defect location and the type of powder (i.e., new or used) was found, the effective defect size parameter based on the Murakami approach (i.e., projected defect area on the loading plane) was compared across all failed specimens. It was found that the fractured specimens fabricated from new powder had an average main defect (i.e., the defect causing fatigue failure) area of $1979 \mu \mathrm{m}^{2}$, while the specimens fabricated from used powder had an average main defect area of $1593 \mu \mathrm{m}^{2}$. These results are in agreement with the previous observations made on the new and used powder characteristics. The used powder was found to have a narrower PSD and a lower BFE when compared to the new powder, indicating a higher flowability for the used powder. This increased flowability can result in a more uniform powder layer distribution. The compressibility of the used powder was also measured to be less, indicating smaller empty spaces within the powder and, consequently, smaller pores in the fabricated parts. Therefore, it may be concluded that recycling Ti-6Al-4V powder in L-PBF can lead to smaller pore sizes and, as a result, longer fatigue lives for machined specimens in the high cycle regime. This can be seen in Figs. 4b, where machined specimens fabricated from used powder and tested under $\varepsilon_{a}=0.004 \mathrm{~mm} / \mathrm{mm}$ had much longer fatigue lives than specimens fabricated from new powder.

\section{CONCLUSION}

Comparison of new and used Ti-6Al-4V Grade 23 powder characteristics, and their effects on the resultant microstructure, tensile deformation, and fatigue behavior of L-PBF Ti-6Al-4V specimens in the as-built and machine surface conditions were investigated. Based on the experimental results and observations, the following conclusions can be made:

1. As a result of a narrower PSD, as well as of lower cohesion and interparticle frictions, the used powder exhibited better flowability as compared to the new powder. The improved flowability and the less compressibility of the used powder may result in smaller internal pores.

2. Powder recycling had negligible effects on the microstructure as no differences in grain size and shape were observed between specimen sets fabricated from new and used powder.

3. Powder recycling did not have any significant effects on the tensile behavior and fatigue performance of the L-PBF Ti-6Al-4V specimens in the as-built surface condition.

4. The effect of powder recycling on the fatigue performance of L-PBF Ti-6Al-4V specimens fab- 
ricated from new and used powder in the machined surface condition was substantial in the high cycle regime, with specimens fabricated from used powder exhibiting significantly longer fatigue lives.

5. The average effective defect size, calculated based on the Murakami approach, was found to be smaller for specimens fabricated from used powder, which can explain their longer high cycle fatigue lives as compared to the specimens fabricated from new powder.

\section{ACKNOWLEDGEMENTS}

This research was partially funded by the $\mathrm{Na}$ tional Science Foundation (NSF) under Grant No. 1657195. The partial support of the Naval Air Systems Command (NAVAIR) is also greatly appreciated.

\section{REFERENCES}

1. J.H. Tan, W.L.E. Wong, and K.W. Dalgarno, Addit. Manuf. 18, 228 (2017).

2. R.M. German, Powder Metallurgy Science (Princeton, NJ: Metal Powder Industries Federation, 1984), p. 1.

3. A.T. Sutton, C.S. Kriewall, M.C. Leu, and J.W. Newkirk, Virtual Phys. Prototyp. 12, 3 (2017).

4. A.T. Sutton, C.S. Kriewall, M.C. Leu, and J.W. Newkirk, Proc. 26th Annu. Int. Solid Free. Fabr. Symp. Addit. Manuf. Conf. 1004 (2016).

5. J.M. Benson and E. Snyders, S. Afr. J. Ind. Eng. 26, 104 (2015).

6. K. Abd-Elghany and D.L. Bourell, Rapid Prototyp. J. 18, 420 (2012).

7. H.P. Tang, M. Qian, N. Liu, X.Z. Zhang, G.Y. Yang, and J. Wang, JOM 67, 555 (2015).

8. P. Nandwana, M.M. Kirka, V.C. Paquit, S. Yoder, and R.R. Dehoff, JOM 70, 1686 (2018)

9. V. Seyda, N. Kaufmann, and C. Emmelmann, Phys. Procedia 39, 425 (2012).

10. B. Liu, R. Wildman, C. Tuck, I. Ashcroft, and R. Hague, Int. Solid Free. Fabr. Symp. Addit. Manuf. Conf. 227 (2011).

11. A. Simchi, Metall. Mater. Trans. B 35, 937 (2004).

12. H. Irrinki, T. Harper, S. Badwe, J. Stitzel, O. Gulsoy, G. Gupta, and S.V. Atre, Prog. Addit. Manuf. 3, 39 (2018).

13. M. Iebba, A. Astarita, D. Mistretta, I. Colonna, M. Liberini, F. Scherillo, C. Pirozzi, R. Borrelli, S. Franchitti, and A. Squillace, J. Mater. Eng. Perform. 26, 4138 (2017).

14. J. Karlsson, A. Snis, H. Engqvist, and J. Lausmaa, J. Mater. Process. Technol. 213, 2109 (2013).

15. J. Clayton, D. Millington-Smith, and B. Armstrong, JOM 67,544 (2015).

16. G. Jacob, C.U. Brown, M.A. Donmez, S.S. Watson, and J. Slotwinski, US Dep. Commer. Natl. Inst. Stand. Technol. (2017).

17. P. Dastranjy Nezhadfar, A. Soltani-Tehrani, A. Sterling, N. Tsolas, and N. Shamsaei, Solid Free. Fabr. Proc. (2018).

18. L.C. Ardila, F. Garciandia, J.B. González-Díaz, P. Álvarez, A. Echeverria, M.M. Petite, R. Deffley, and J. Ochoa, Phys. Procedia 56, 99 (2014).
19. P. Nandwana, W.H. Peter, R.R. Dehoff, L.E. Lowe, M.M. Kirka, F. Medina, and S.S. Babu, Metall. Mater. Trans. B 47,754 (2016).

20. R.O'Leary, R. Setchi, P. Prickett, G. Hankins, and N. Jones, 2nd Int. Conf. Sustain. Des. Manuf. 14 (2015).

21. A. Strondl, O. Lyckfeldt, H. Brodin, and U. Ackelid, JOM 67, 549 (2015).

22. P.E. Carrion, A. Soltani-Tehrani, S.M. Thompson, and N. Shamsaei, Solid Free (Proc: Fabr, 2018).

23. Y.Y. Sun, S. Gulizia, C.H. Oh, C. Doblin, Y.F. Yang, and M. Qian, JOM 67, 564 (2015).

24. ASTM F2924-14, ASTM Int., West Conshohocken, PA, 10.04 (2014).

25. M. Seifi, M. Gorelik, J. Waller, N. Hrabe, N. Shamsaei, S. Daniewicz, and J.J. Lewandowski, JOM 69, 439 (2017).

26. N. Shamsaei, A. Yadollahi, L. Bian, and S.M. Thompson, Addit. Manuf. 8, 12 (2015).

27. M. Seifi, A. Salem, J. Beuth, O. Harrysson, and J.J. Lewandowski, JOM (2016).

28. J.J. Lewandowski and M. Seifi, Annu. Rev. Mater. Res. 46, 151 (2016).

29. ASTM E2651-13, ASTM Int., West Conshohocken, PA, 14.02 (2013).

30. ASTM B215-15, ASTM Int., West Conshohocken, PA, 02.05 (2015).

31. ASTM E1409-13, ASTM Int., West Conshohocken, PA, 03.05 (2013).

32. ASTM E8/E8M-16a, ASTM Int., West Conshohocken, PA, 03.01 (2016).

33. ASTM E606/E606M-12, ASTM Int., West Conshohocken, PA, 03.01 (2012).

34. X. Fu, D. Huck, L. Makein, B. Armstrong, U. Willen, and T. Freeman, Particuology 10, 203 (2012).

35. L.C. Wei, L.E. Ehrlich, M.J. Powell-Palm, C. Montgomery, J. Beuth, and J.A. Malen, Addit. Manuf. 21, 201 (2018)

36. O.A. Quintana and W. Tong, JOM 12, 2693 (2017).

37. P.E. Carrion, N. Shamsaei, S.R. Daniewicz, and R.D. Moser, Int. J. Fatigue 99, 87 (2017)

38. A.B. Spierings and G. Levy, Solid Free. Fabr. Proc. 342 (2009).

39. A.B. Spierings, N. Herres, and G. Levy, Rapid Prototyp. J. 17, 195 (2011).

40. C. Meier, R. Weissbach, J. Weinberg, W.A. Wall, and A.J.J. Hart, ArXiv Prepr. ArXiv1804.06816 (2018).

41. J. Pegues, M. Roach, R. Scott Williamson, and N. Shamsaei, Int. J. Fatigue 116, 543 (2018)

42. A. Yadollahi and N. Shamsaei, Int. J. Fatigue 98, 14 (2017).

43. Y. Murakami, Metal Fatigue: Effects of Small Defects and Nonmetallic Inclusions (Kidlington, Oxford: Elsevier, 2002), p. 75 .

44. S. Leuders, M. Vollmer, F. Brenne, T. Tröster, and T. Niendorf, Metall. Mater. Trans. A 46, 3816 (2015).

45. J. Günther, D. Krewerth, T. Lippmann, S. Leuders, T. Tröster, A. Weidner, H. Biermann, and T. Niendorf, Int. J. Fatigue 94, 236 (2017).

46. E. Wycisk, S. Siddique, D. Herzog, F. Walther, and C. Emmelmann, Front. Mater. 2, 72 (2015).

47. S. Romano, A. Brandão, J. Gumpinger, M. Gschweitl, and S. Beretta, Mater. Des. 131, 32 (2017).

48. S. Beretta and S. Romano, Int. J. Fatigue 94, 178 (2017). 